Supporting Information for:

\title{
Direct Observation of the Hole Carriers in DNA Photoinduced Charge Transport
}

Michelle A. Harris, Ashutosh Kumar Mishra, Ryan M. Young, Kristen E. Brown, Michael R.

Wasielewski,* and Frederick D. Lewis*

Department of Chemistry and Argonne-Northwestern Solar Energy Research (ANSER) Center,

Northwestern University, Evanston, Illinois 60208-3113

\begin{tabular}{|c|c|}
\hline Page & Content \\
\hline 2 & Preparation of DPA-linked hairpins and Table $\mathrm{S} 1 \mathrm{of} \mathrm{m} / \mathrm{z}$ values for oligomer sequences \\
\hline 3 & Transient absorption and Raman spectroscopy collection and analysis methods \\
\hline 5 & $\begin{array}{l}\text { Singular value decomposition (SVD) global fit and species associated spectra (SAS) for } \\
\text { hairpins DPA-G and DPA-A } \mathrm{A}_{1} \mathrm{G} \text { (Figs. S1 and S2) }\end{array}$ \\
\hline 6 & $\begin{array}{l}\text { SVD and SAS for hairpin DPA-A } \mathrm{G} \text { (Fig. S3) and multi-exponential fitting for decay of } \\
\mathrm{DPA}^{-}-\mathrm{A}_{2}^{+} \mathrm{G} \text { (Fig S4) }\end{array}$ \\
\hline 7 & $\begin{array}{l}\text { SVD and SAS for the fsTA spectra (Fig. S5) and Modified global fit (MGF) and SAS for } \\
\text { the nsTA spectra (Fig. S6) of DPA-A }{ }_{3} G\end{array}$ \\
\hline 8 & MGF and SAS for the fsTA spectra (Fig. S7) and nsTA spectra (Fig. S8) of DPA-A ${ }_{4} G$ \\
\hline 9 & MGF and SAS for the fsTA spectra (Fig. S9) and nsTA spectra (Fig. S10) of DPA-A $\mathrm{A}_{5} \mathrm{G}$ \\
\hline 10 & MGF and SAS for the fsTA spectra (Fig. S11) and nsTA spectra (Fig. S12) of DPA-A ${ }_{6}$ G \\
\hline 11 & $\begin{array}{l}\text { SVD and SAS for the fsTA spectra (Fig. S13) and MGF and SAS for the nsTA spectra } \\
\text { (Fig. S14) of DPA-A } 6\end{array}$ \\
\hline 12 & Selected FSRS (Fig. S15) and MGF and SAS for the FSRS of DPA-G (Fig. S16) \\
\hline 13 & Selected FSRS (Fig. S17) and MGF and SAS for the FSRS of DPA-AG (Fig. S18) \\
\hline 14 & Selected FSRS (Fig. 19) and MGF and SAS for the FSRS of DPA-A ${ }_{2}$ G (Fig. S20) \\
\hline 15 & Selected FSRS (Fig. S21) and MGF and SAS for the FSRS of DPA-A 3 G (Fig. S22) \\
\hline 16 & Selected FSRS for DPA-A 6 (Fig. S23) \\
\hline 17 & Lorenztian fits of features from charge separated species in all DPA hairpins (Fig. S24) \\
\hline 18 & Table of values from Lorentzian fits (Table S2) \\
\hline 19 & References for Supporting Information \\
\hline
\end{tabular}




\section{Preparation of DPA-Linked Hairpins.}

Diphenylacetylene-4,4'-dicarboxylic acid was prepared and converted to its $N, N^{\prime}$-dihydroxyproplyamide as previously described. ${ }^{1}$ The dihydroxypropylamide linker was incorporated into the hairpins in Chart 1 (main text) by the method of Letsinger and $\mathrm{Wu}^{2}$ The hairpins were purified to a single peak ( $>98 \%$ ) by reverse phase HPLC and characterized by MALDI-TOF mass spectrometry (Table S1).

Table S1. m/z values for oligomer sequences determined by MALDI-TOF mass spectrometry

\begin{tabular}{lcc}
\hline Hairpin & Calculated & Experimental \\
\hline DPA-A $_{6}$ & 4092.16 & 4095.20 \\
DPA-G & 4712.16 & 4711.66 \\
DPA-A ${ }_{1} \mathrm{G}$ & 4712.16 & 4712.25 \\
DPA-A ${ }_{2} \mathrm{G}$ & 4712.16 & 4713.87 \\
DPA-A ${ }_{3} \mathrm{G}$ & 4712.16 & 4711.67 \\
DPA-A & 4712.16 & 4711.02 \\
DPA-A ${ }_{5} \mathrm{G}$ & 4712.16 & 4711.66 \\
DPA-A & 5331.16 & 5327.67
\end{tabular}


Transient Absorption Spectroscopy. Femtosecond transient absorption (fsTA) spectra were obtained using an apparatus reported previously. ${ }^{3}$ Samples were prepared in $2 \mathrm{~mm}$ cuvettes and excited with a $0.7 \mu \mathrm{J}$ laser pulse at $330 \mathrm{~nm}$ using a commercial non-collinear optical parametric amplifier (TOPAS-White, Light-Conversion LLC). A lower excitation pump pulse energy was used than previous experiments $(1 \mu \mathrm{J} /$ pulse) as a precaution to prevent degradation. Samples were also stirred to reduce the effects of local heating and sample degradation. For nanosecond transient absorption experiments (nsTA), solutions were prepared in $2 \mathrm{~mm}$ cuvettes, deoxygenated by bubbling with nitrogen for 30 minutes, and excited with a $1 \mu \mathrm{J}$ laser pulse at $330 \mathrm{~nm}$. The nsTA experiments used an amplified femtosecond laser for the pump and a commercial spectrometer (EOS, Ultrafast Systems) for the probe as described previously. ${ }^{4}$

Femtosecond Stimulated Raman Spectroscopy. Femtosecond stimulated Raman spectroscopy (FSRS) was performed using a Ti:sapphire based apparatus previously described. ${ }^{5}$ The spectra are acquired after exciting DPA with a $330 \mathrm{~nm}$ actinic pump and using a $575 \mathrm{~nm}$ Raman pump on resonance with the $\mathrm{G}^{+\bullet}$ absorption transition.

Data Analysis. All global analysis and modified global analysis was fit to the solution of a first order model convoluted with a Gaussian instrument response function using an in-house written program in Matlab (The Mathworks, Inc.) previously described. ${ }^{6}$ The fsTA data for most hairpins were analyzed using a singular value decomposition (SVD) global fit. The fsTA data for hairpins DPA-A4-6 were analyzed with a modified global fit (MGF) performed by simultaneously fitting multiple wavelengths of key features as labeled in Figures S7-S9. A modified global fit was more accurate than SVD global fit in these cases since complete hole 
arrival on $\mathrm{G}$ does not happen until after the time window of the fsTA instrument, ca. 8 ns, and the SVD is less accurate in such cases versus an MGF. The decay of the A-polaron feature separate from the decay of the $\mathrm{DPA}^{-\bullet}$ features was corroborated by the fsTA spectra at $6 \times \tau$ comparing the spectra after injection to those after the A-polaron decay when only the DPA ${ }^{-}$ feature remains (Figure 2). Multi-exponential fitting convoluted with the instrument response of $577 \mathrm{~nm}$ and $1131 \mathrm{~nm}$ for the A-polaron and $\mathrm{DPA}^{-\bullet}$ respectively was used to determine the decay constant of the $\mathrm{DPA}^{-\bullet}-\mathrm{A}_{2}{ }^{+\bullet} \mathrm{G}$ which is too subtle to detect through a global fit (Figure S4).

Analysis of the nsTA used a MGF using multiple wavelength at key features as indicated in Figures S10-S13. The MGF was more accurate in this case due to the inherently lower signalto-noise in the NIR region caused by the probe.

The FSRS spectra were also analyzed using MGF (Figure S15, S17, S19, and S21). Here the MGF was more accurate than the SVD fit due to the low signal to noise typical of FSRS.

The efficiency of hole transport to $\mathrm{G}\left(\Phi_{\mathrm{G}}\right.$, Table 1$)$ was estimated by comparing the area of the $\mathrm{DPA}^{-\bullet}$ feature at $1130 \mathrm{~nm}$ at a time after injection $\left(6 \times \tau_{\text {inj }}\right)$ and at complete hole arrival on G $\left(6 \times \tau_{\mathrm{ag}}\right)$. The NIR feature allows for a more accurate calculation of $\Phi_{\mathrm{g}}$ than does the $490 \mathrm{~nm}$ band since it is not convolved with other spectral features of $\mathrm{DPA}^{-\bullet}$ or $\mathrm{A}_{n}^{+\bullet}$ and $\mathrm{G}^{+\bullet}$. 

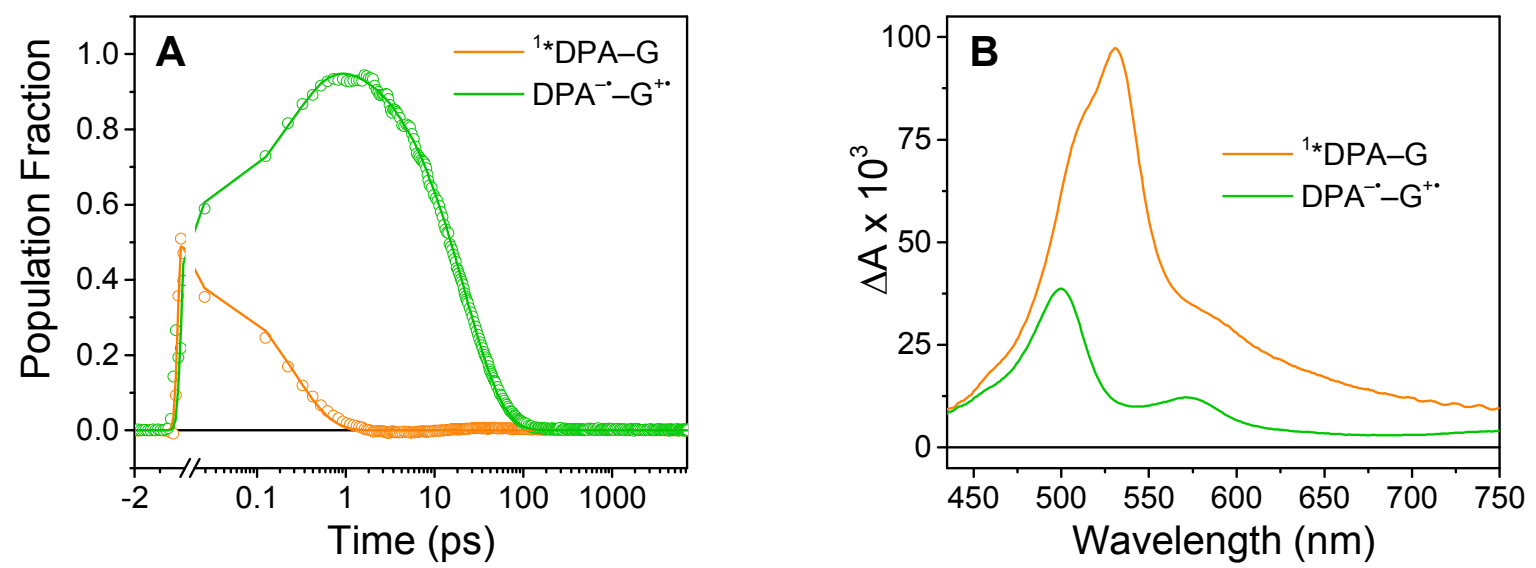

Figure S1. (A) SVD global fit of DPA-G. The raw data (o) and fits (-) are labeled according to the associated species. (B) The Species Associated Spectra (SAS) of the fsTA spectra for DPA-G obtained when exciting at $330 \mathrm{~nm}$ and probing in the visible. The associated species are labeled. SVD global fit including the NIR was unable to detect the rise of the anion due to the subtle changes in the NIR, but did show a similar charge recombination time. ${ }^{1}$ *DPA-G has a lifetime of $\tau_{\text {inj }}=0.255 \pm 0.003$ ps. DPA ${ }^{-}-\mathrm{G}^{+\bullet}$ has a lifetime of $\tau_{\text {crg }}=22.2 \pm 0.4 \mathrm{ps}$. Note that the error of the instrument is $\sim 0.2 \mathrm{ps}$ and is the minimum possible error regardless of smaller errors calculated by the program.
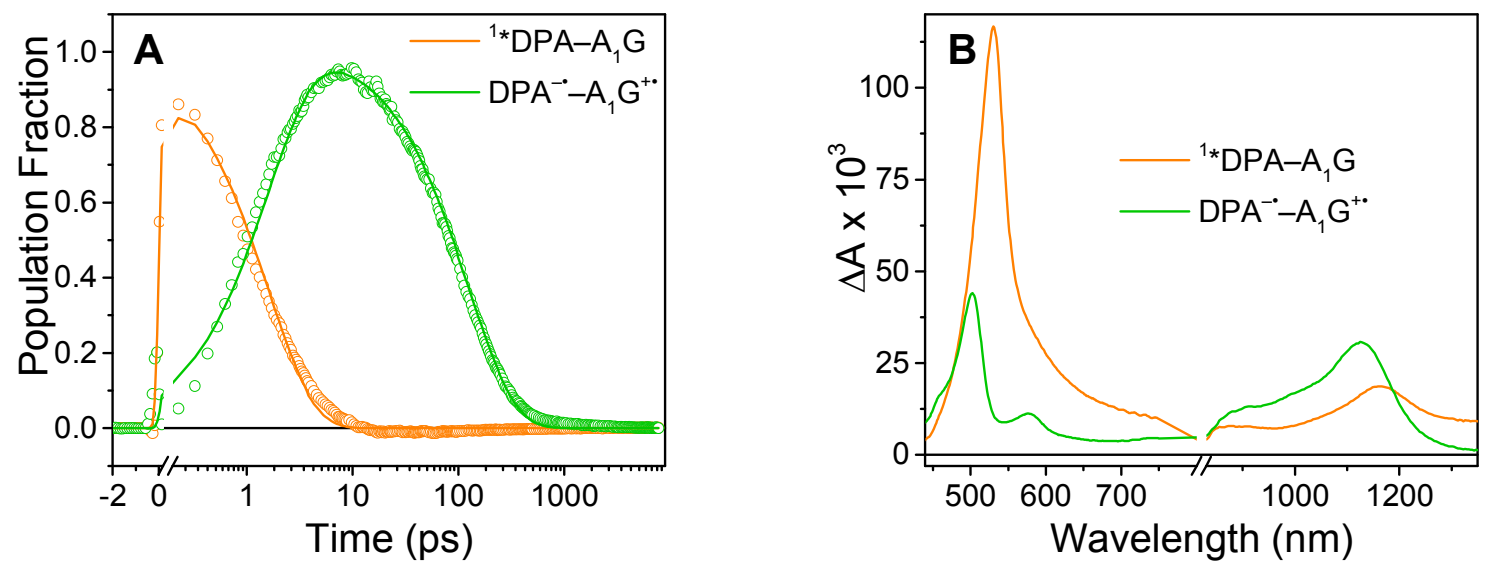

Figure S2. (A) SVD global fit of DPA- $\mathrm{A}_{1} \mathrm{G}$. The raw data (o) and fits (-) are labeled according to the associated species. (B) The Species Associated Spectra (SAS) of the fsTA spectra for DPA-A $\mathrm{A}$ obtained when exciting at $330 \mathrm{~nm}$ and probing in the visible and NIR regions. The associated species are labeled. ${ }^{1}{ }^{*} \mathrm{DPA}-\mathrm{A}_{1} \mathrm{G}$ has a lifetime of $\tau_{\mathrm{inj}}=1.62 \mathrm{ps} \pm 0.02$ ps and $\mathrm{DPA}^{-\bullet}-\mathrm{A}_{1} \mathrm{G}^{+\bullet}$ has a lifetime of $\tau_{\mathrm{crg}}=128 \pm 3 \mathrm{ps}$. Note that the error of the instrument is $\sim 0.2 \mathrm{ps}$ and is the minimum possible error regardless of smaller errors calculated by the program. 

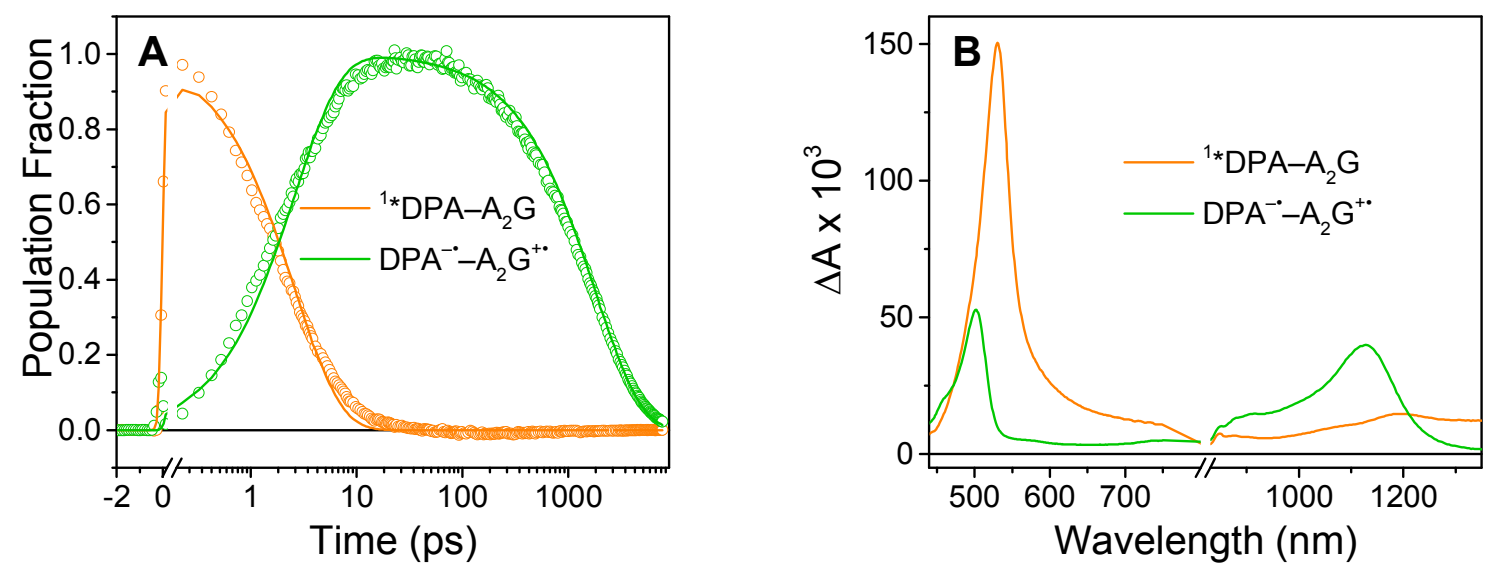

Figure S3. (A) SVD global fit of DPA- $\mathrm{A}_{2} \mathrm{G}$. The raw data (o) and fits (-) are labeled according to the associated species. (B) The Species Associated Spectra (SAS) of the fsTA spectra for DPA- $\mathrm{A}_{2} \mathrm{G}$ obtained when exciting at $330 \mathrm{~nm}$ and probing in the visible and NIR regions. The associated species are labeled. ${ }^{*} \mathrm{DPA}-\mathrm{A}_{2} \mathrm{G}$ has a lifetime of $\tau_{\mathrm{inj}}=2.63 \mathrm{ps} \pm 0.05$ ps. $\mathrm{DPA}^{-}-\mathrm{A}_{2} \mathrm{G}^{+\bullet}$ has a lifetime of $\tau_{\text {crg }}=1.81 \pm 0.06 \mathrm{~ns}$. Note that the error of the instrument is $\sim 0.2 \mathrm{ps}$ and is the minimum possible error regardless of smaller errors calculated by the program.
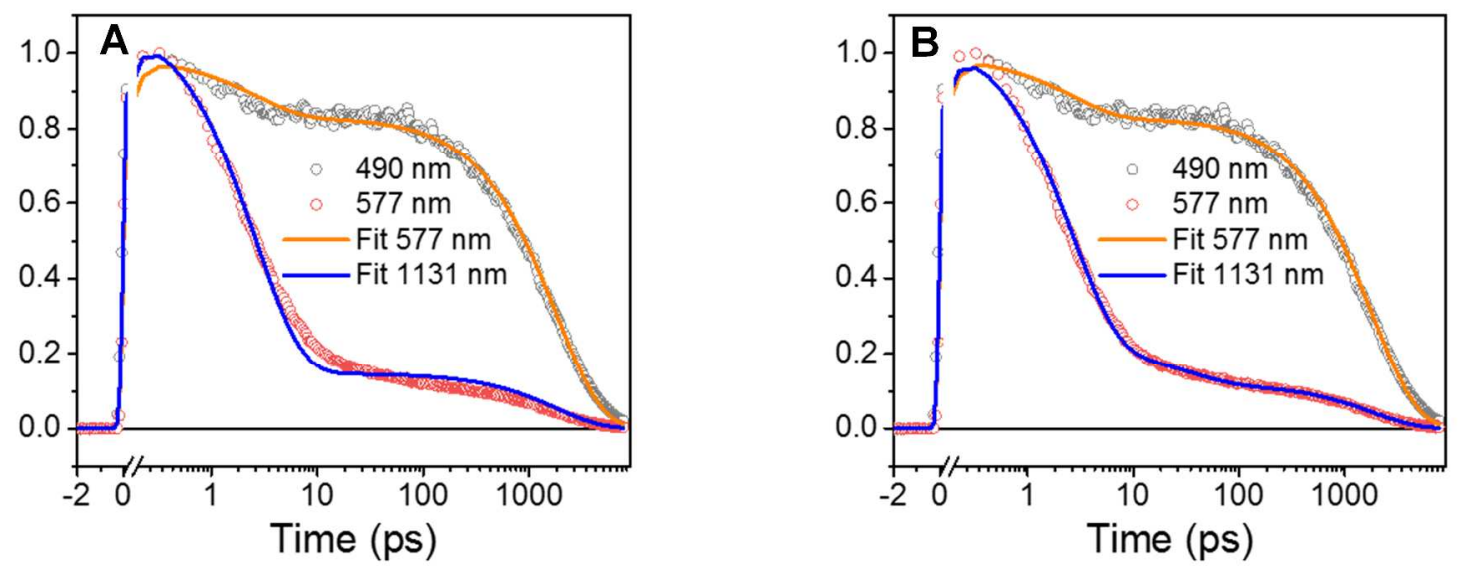

Figure S4. A global, multi-exponential fitting of $490 \mathrm{~nm}$ and $577 \mathrm{~nm}$ at the peak of the DPA ${ }^{-}$ and the A-polaron, respectively, was used to determine the decay of the $\mathrm{DPA}^{-{ }^{-}}-\mathrm{A}_{2}{ }^{+\bullet} \mathrm{G}$. (A) Two-exponential fit with components $2.63 \mathrm{ps}$ and $1.81 \mathrm{~ns}$ fixed based on the SVD global fit in Figure S3. (B) Three-exponential fit with components $2.63 \mathrm{ps}$ and $1.81 \mathrm{~ns}$ fixed based on the SVD global fit in Figure S3. The third decay component is $33.8 \mathrm{ps} \pm 4$ ps. At $577 \mathrm{~nm}$, the component contributes to $12 \%$ of the total relative amplitude change and $56 \%$ of the relative amplitude change after decay of the ${ }^{1 *}$ DPA. This component was not picked up by the SVD global fit because of its negligible contribution to the decay of the key DPA ${ }^{-}$features at 490 $\mathrm{nm}$ of $0.4 \%$ 

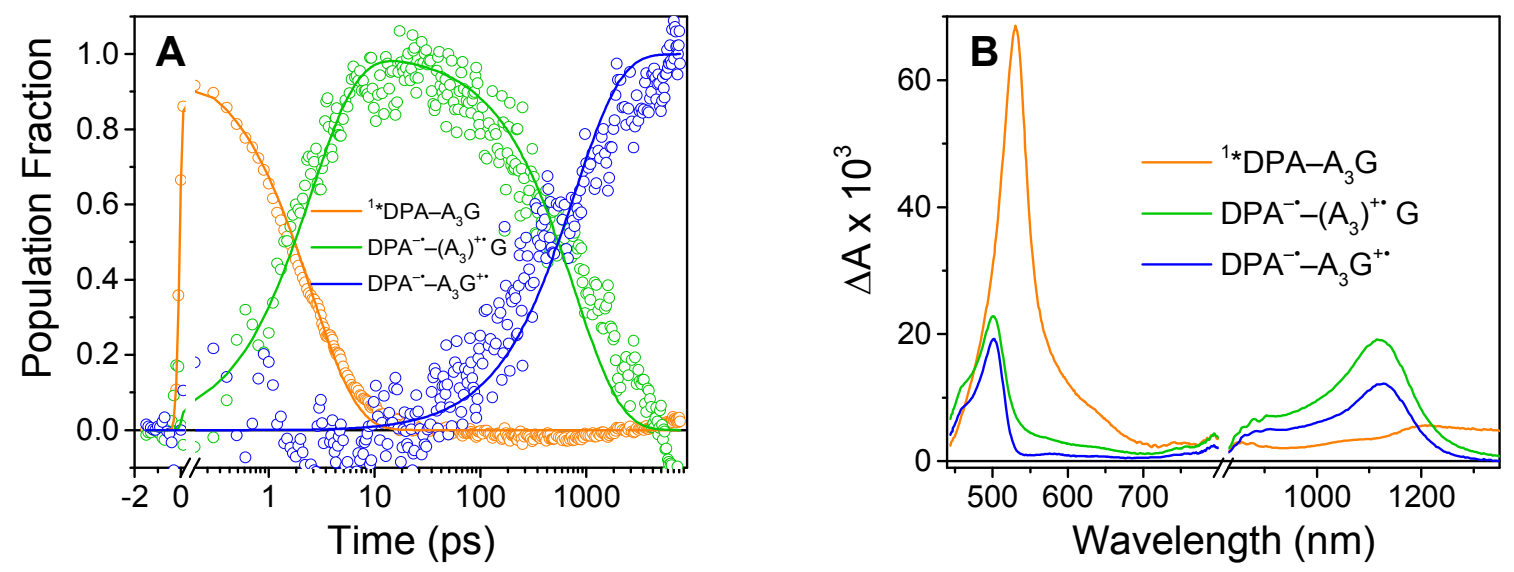

Figure S5. (A) SVD global fit of $\mathrm{D}-\mathrm{A}_{3} \mathrm{G}$. The raw data (o) and fits (-) are labeled according to the associated species. (B) The Species Associated Spectra (SAS) of the fsTA spectra for DPA $-\mathrm{A}_{3} \mathrm{G}$ obtained when exciting at $330 \mathrm{~nm}$ and probing in the visible and NIR regions. The associated species are labeled. ${ }^{1}{ }^{*} \mathrm{DPA}-\mathrm{A}_{3} \mathrm{G}$ has a lifetime of $\tau_{\mathrm{inj}}=2.55 \mathrm{ps} \pm 0.05 \mathrm{ps}$. DPA ${ }^{-\bullet}$ $\left(\mathrm{A}_{3}\right)^{+\bullet} \mathrm{G}$ has a lifetime of $\tau_{\mathrm{a}}=785 \pm 20 \mathrm{ps}$. DPA ${ }^{-\bullet}-\mathrm{A}_{3} \mathrm{G}^{+\bullet}$ has a lifetime greater than the time window of the fsTA, $>5 \mathrm{~ns}$. Note that the error of the instrument is $\sim 0.2 \mathrm{ps}$ and is the minimum possible error regardless of smaller errors calculated by the program.
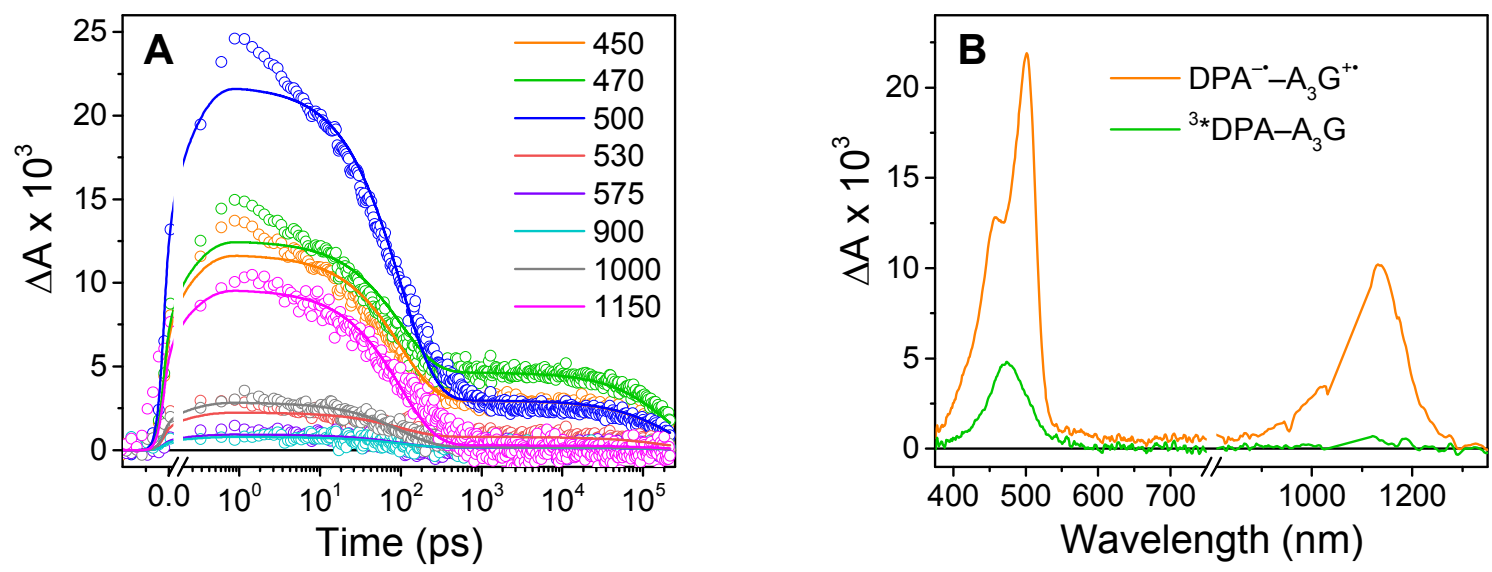

Figure S6. Modified global fit (-) and raw data (o) of indicated key wavelengths (A) and the Species Associated Spectra (SAS) (B) of a first order model of the nsTA spectra for DPA$\mathrm{A}_{3} \mathrm{G}$ obtained when exciting at $330 \mathrm{~nm}$ and probing in the visible and NIR regions. The associated species are labeled. $\mathrm{DPA}^{-\bullet}-\mathrm{A}_{3} \mathrm{G}^{+\bullet}$ has a lifetime of $\tau_{\text {crg }}=101 \pm 0.8 \mathrm{~ns}$. The triplet lifetime for ${ }^{3 *} \mathrm{DPA}, 200 \pm 0.7 \mu \mathrm{s}$, is inaccurate considering the temporal window extends to only $200 \mu$ s and so the lifetime of ${ }^{3 * D P A}$ is given the limit of $>100 \mu$ s. Note that the error of the instrument is $\sim 0.6 \mathrm{~ns}$ and is the minimum possible error regardless of smaller errors calculated by the program. 

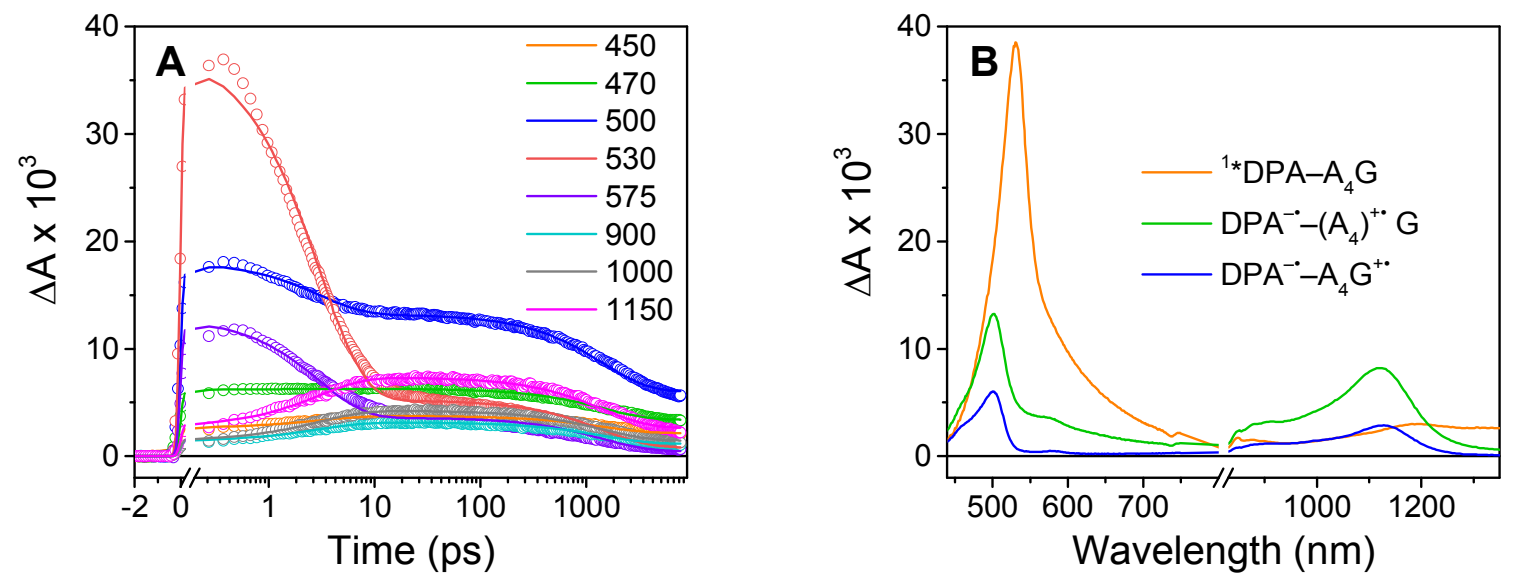

Figure S7. Modified global fit (-) and raw data (o) of indicated key wavelengths (A) and the Species Associated Spectra (SAS) (B) of a first order model of the fsTA spectra for DPA$\mathrm{A}_{4} \mathrm{G}$ obtained when exciting at $330 \mathrm{~nm}$ and probing in the visible and NIR regions. The associated species are labeled. ${ }^{1}{ }^{*} \mathrm{DPA}-\mathrm{A}_{4} \mathrm{G}$ has a lifetime of $\tau_{\mathrm{inj}}=3.02 \mathrm{ps} \pm 0.02 \mathrm{ps}$. DPA ${ }^{-}-$ $\left(\mathrm{A}_{4}\right)^{+\bullet} \mathrm{G}$ has a lifetime of $\tau_{\mathrm{a}}=1.47 \pm 0.02 \mathrm{~ns}$. $\mathrm{DPA}^{-\bullet}-\mathrm{A}_{4} \mathrm{G}^{+\bullet}$ has a lifetime greater than the time window of the fsTA, $>5 \mathrm{~ns}$. Note that the error of the instrument is $\sim 0.2 \mathrm{ps}$ and is the minimum possible error regardless of smaller errors calculated by the program.
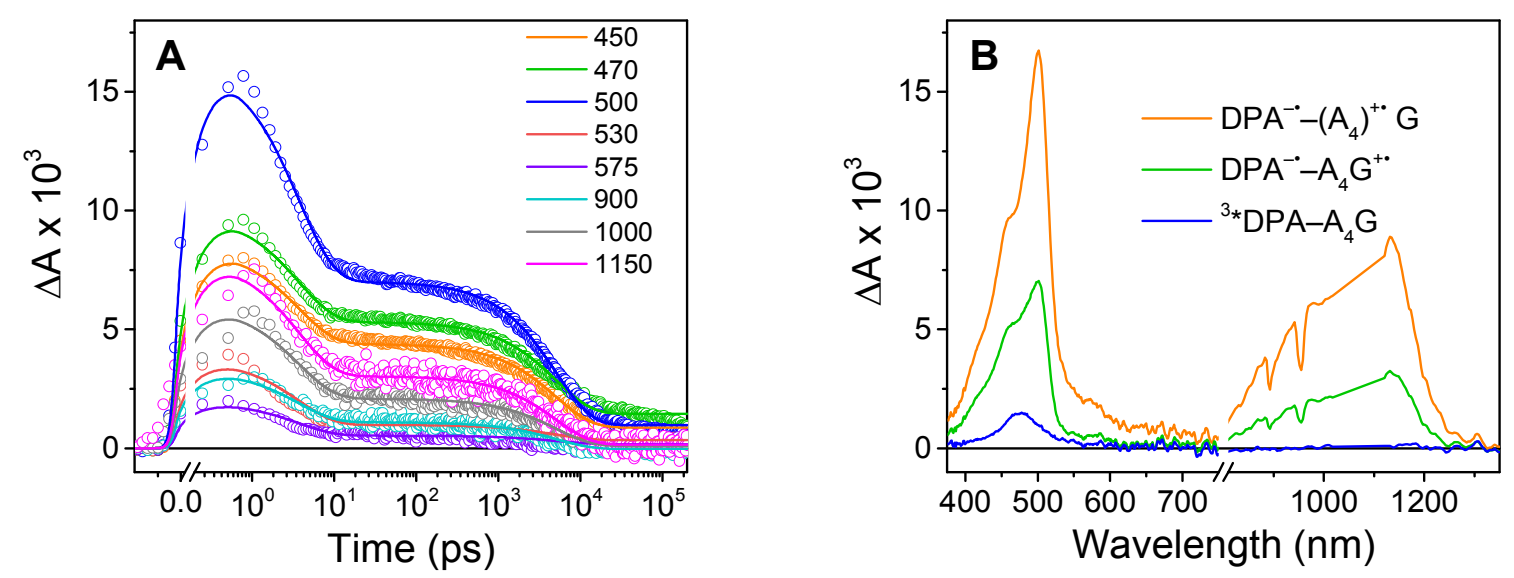

Figure S8. Modified global fit (-) and raw data (o) of indicated key wavelengths (A) and the Species Associated Spectra (SAS) (B) of a first order model of the nsTA spectra for DPA$\mathrm{A}_{4} \mathrm{G}$ obtained when exciting at $330 \mathrm{~nm}$ and probing in the visible and NIR regions. The associated species are labeled. $\mathrm{DPA}^{-}-\left(\mathrm{A}_{4}\right)^{+\bullet} \mathrm{G}$ has a lifetime of $3.76 \pm 0.6 \mathrm{~ns}$. The decay constant for the A-polaron measured using the nsTA is less accurate than the fsTA due to the longer step size chosen for obtaining the nsTA out to $200 \mu \mathrm{s}$. For decay constants $<5 \mathrm{~ns}$, the fsTA is more accurate and hence this value is the reported value. $\mathrm{DPA}^{-\bullet}-\mathrm{A}_{4} \mathrm{G}^{+\bullet}$ has a lifetime of $\tau_{\mathrm{crg}}=5.12 \pm 0.3 \mu \mathrm{s}$. The lifetime of ${ }^{3 *} \mathrm{DPA}$ is given the limit of $>100 \mu$ s considering the temporal window extends to only $200 \mu \mathrm{s}$. Note that the error of the instrument is $\sim 0.6 \mathrm{~ns}$ and is the minimum possible error regardless of smaller errors calculated by the program. 

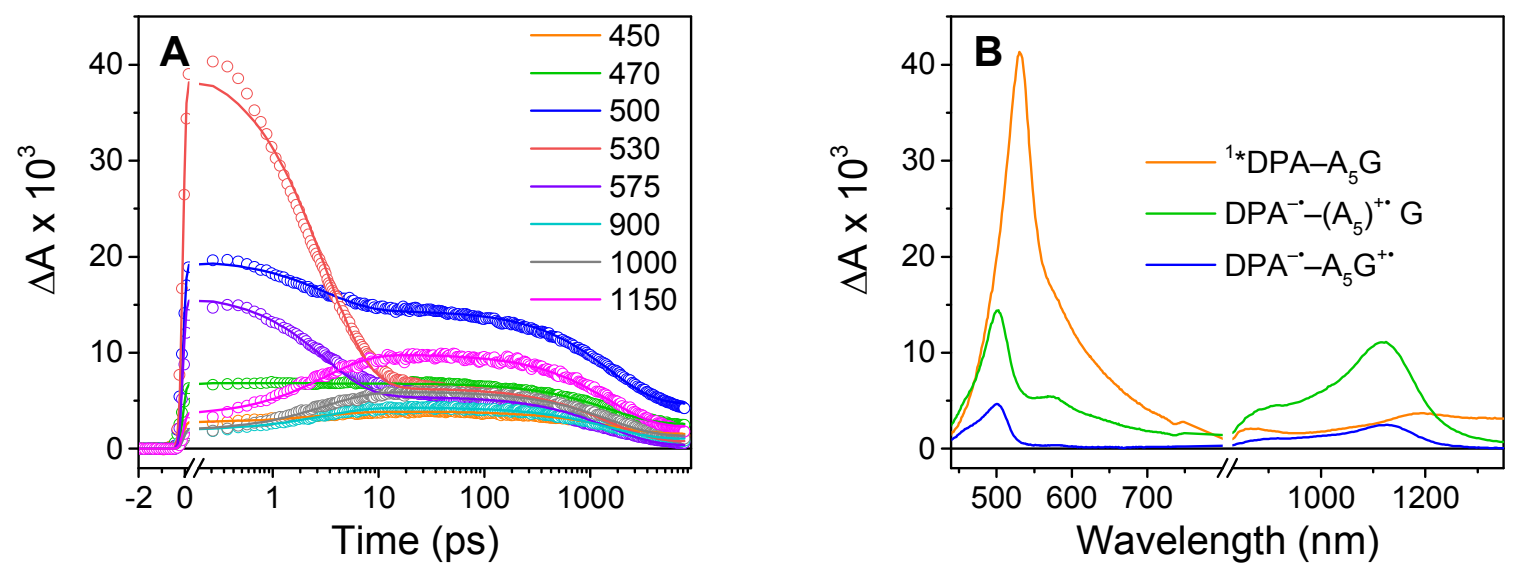

Figure S9. Modified global fit (-) and raw data (o) of indicated key wavelengths (A) and the Species Associated Spectra (SAS) (B) of a first order model of the fsTA spectra for DPA$\mathrm{A}_{5} \mathrm{G}$ obtained when exciting at $330 \mathrm{~nm}$ and probing in the visible and NIR regions. The associated species are labeled. ${ }^{1} * \mathrm{DPA}-\mathrm{A}_{5} \mathrm{G}$ has a lifetime of $\tau_{\mathrm{inj}}=3.12 \mathrm{ps} \pm 0.02 \mathrm{ps}$. $\mathrm{DPA}^{-}-$ $\left(\mathrm{A}_{5}\right)^{+\bullet} \mathrm{G}$ has a lifetime of $\tau_{\mathrm{a}}=1.52 \pm 0.02 \mathrm{~ns}$. $\mathrm{DPA}^{-\bullet}-\mathrm{A}_{5} \mathrm{G}^{+\bullet}$ has a lifetime greater than the time window of the fsTA, $>5 \mathrm{~ns}$. Note that the error of the instrument is $\sim 0.2 \mathrm{ps}$ and is the minimum possible error regardless of smaller errors calculated by the program.
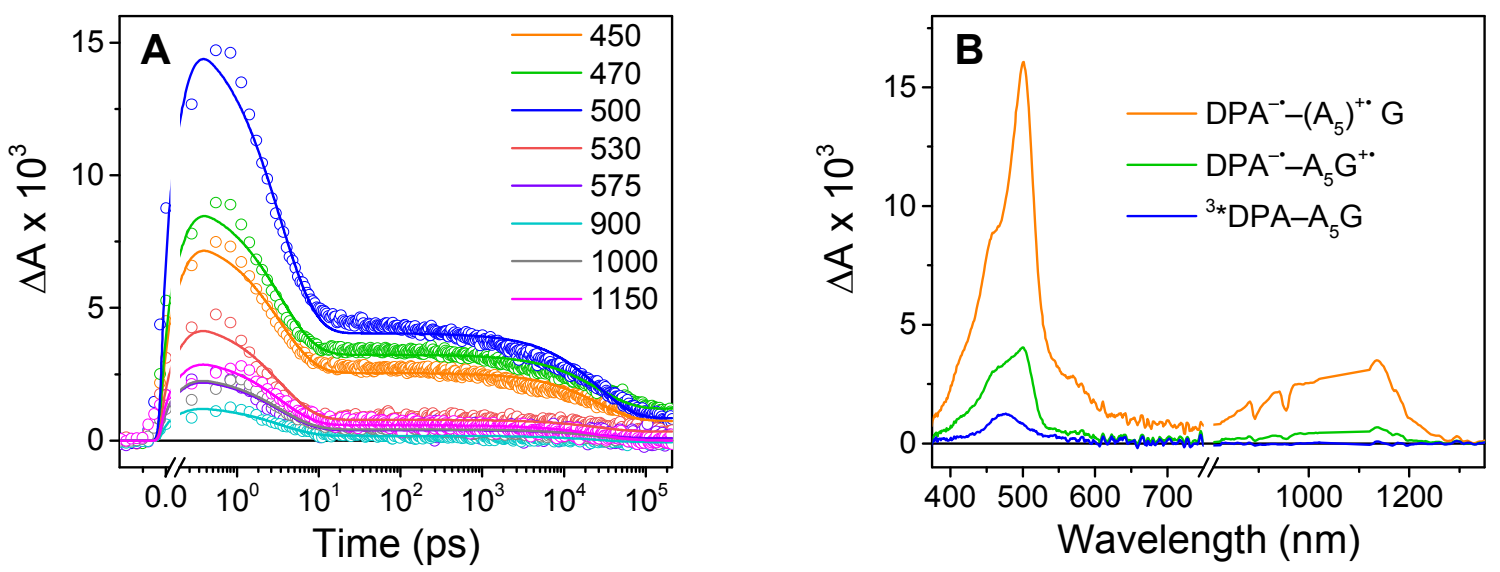

Figure S10. Modified global fit (-) and raw data (o) of indicated key wavelengths (A) and the Species Associated Spectra (SAS) (B) of a first order model of the nsTA spectra for DPA$\mathrm{A}_{5} \mathrm{G}$ obtained when exciting at $330 \mathrm{~nm}$ and probing in the visible and NIR regions. The associated species are labeled. $\mathrm{DPA}^{-\bullet}-\left(\mathrm{A}_{5}\right)^{+\bullet} \mathrm{G}$ has a lifetime of $3.40 \pm 0.1 \mathrm{~ns}$. The decay constant for the A-polaron measured using the nsTA is less accurate than the fsTA due to the longer step size chosen for obtaining the nsTA out to $200 \mu \mathrm{s}$. For decay constants $<5 \mathrm{~ns}$, the fsTA is more accurate and hence this value is the reported value. $\mathrm{DPA}^{-\bullet}-\mathrm{A}_{5} \mathrm{G}^{+\bullet}$ has a lifetime of $\tau_{\mathrm{crg}}=26.9 \pm 0.2 \mu \mathrm{s}$. The lifetime of ${ }^{3 * D P A}$ is given the limit of $>100 \mu$ s considering the temporal window extends to only $200 \mu \mathrm{s}$. Note that the error of the instrument is $\sim 0.6 \mathrm{~ns}$ and is the minimum possible error regardless of smaller errors calculated by the program. 

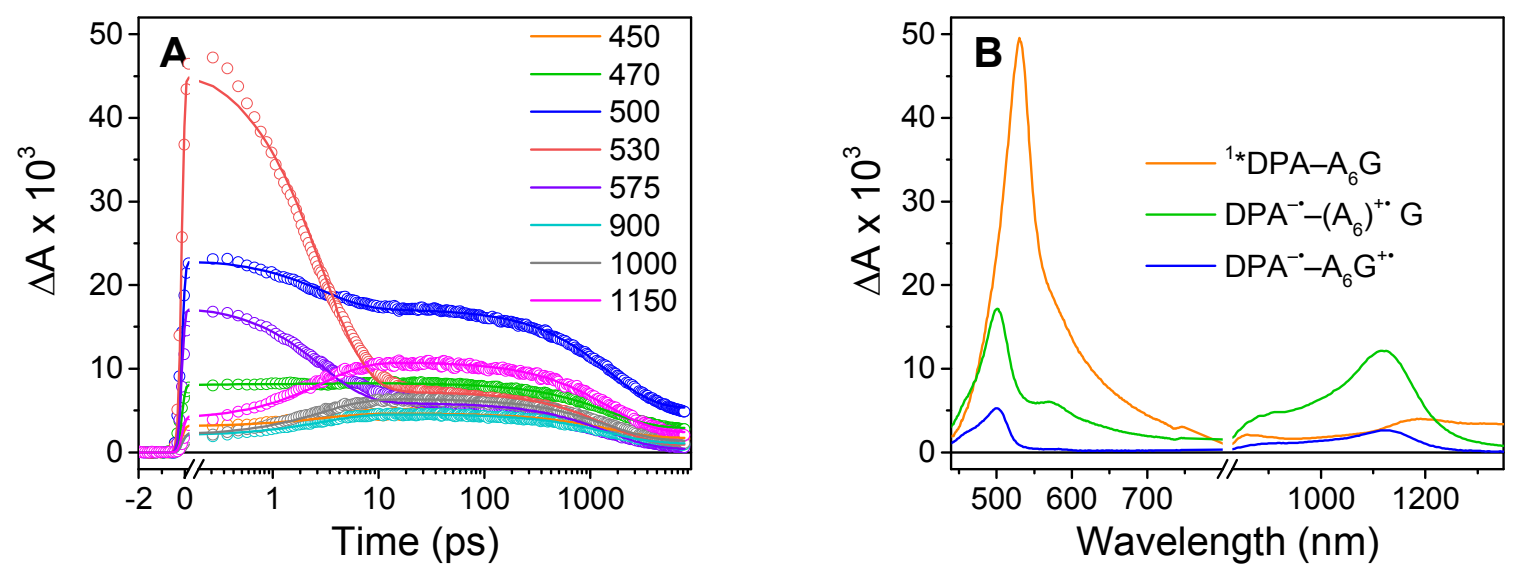

Figure S11. Modified global fit (-) and raw data (o) of indicated key wavelengths (A) and the Species Associated Spectra (SAS) (B) of a first order model of the fsTA spectra for DPA$\mathrm{A}_{6} \mathrm{G}$ obtained when exciting at $330 \mathrm{~nm}$ and probing in the visible and NIR regions. The associated species are labeled. ${ }^{1} * \mathrm{DPA}-\mathrm{A}_{6} \mathrm{G}$ has a lifetime of $\tau_{\mathrm{inj}}=2.93 \mathrm{ps} \pm 0.02 \mathrm{ps}$. $\mathrm{DPA}^{-}-$ $\left(\mathrm{A}_{6}\right)^{+\bullet} \mathrm{G}$ has a lifetime of $\tau_{\mathrm{a}}=1.53 \pm 0.02 \mathrm{~ns}$. $\mathrm{DPA}^{-\bullet}-\mathrm{A}_{6} \mathrm{G}^{+\bullet}$ has a lifetime greater than the time window of the fsTA, $>5 \mathrm{~ns}$. Note that the error of the instrument is $\sim 0.2 \mathrm{ps}$ and is the minimum possible error regardless of smaller errors calculated by the program.
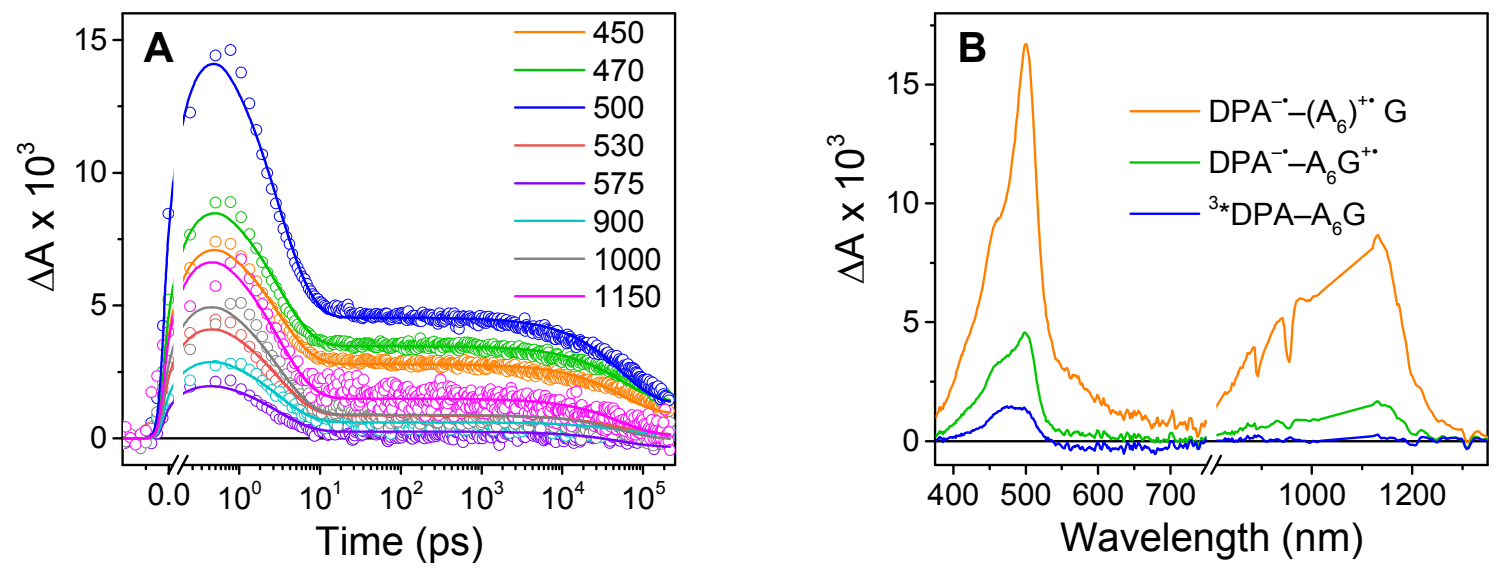

Figure S12. Modified global fit (-) and raw data (o) of indicated key wavelengths (A) and the Species Associated Spectra (SAS) (B) of a first order model of the nsTA spectra for DPA$\mathrm{A}_{6} \mathrm{G}$ obtained when exciting at $330 \mathrm{~nm}$ and probing in the visible and NIR regions. The associated species are labeled. $\mathrm{DPA}^{-\bullet}-\left(\mathrm{A}_{6}\right)^{+\bullet} \mathrm{G}$ has a lifetime of $3.40 \pm 0.1 \mathrm{~ns}$. The decay constant for the A-polaron measured using the nsTA is less accurate than the fsTA due to the longer step size chosen for obtaining the nsTA out to $200 \mu \mathrm{s}$. For decay constants $<5 \mathrm{~ns}$, the fsTA is more accurate and hence this value is the reported value. DPA ${ }^{-}-\mathrm{A}_{6} \mathrm{G}^{+\bullet}$ has a lifetime of $\tau_{\mathrm{crg}}=26.9 \pm 0.2 \mu \mathrm{s}$. The lifetime of ${ }^{3 *} \mathrm{DPA}$ is given the limit of $>100 \mu$ s considering the temporal window extends to only $200 \mu \mathrm{s}$. Note that the error of the instrument is $\sim 0.6 \mathrm{~ns}$ and is the minimum possible error regardless of smaller errors calculated by the program. 

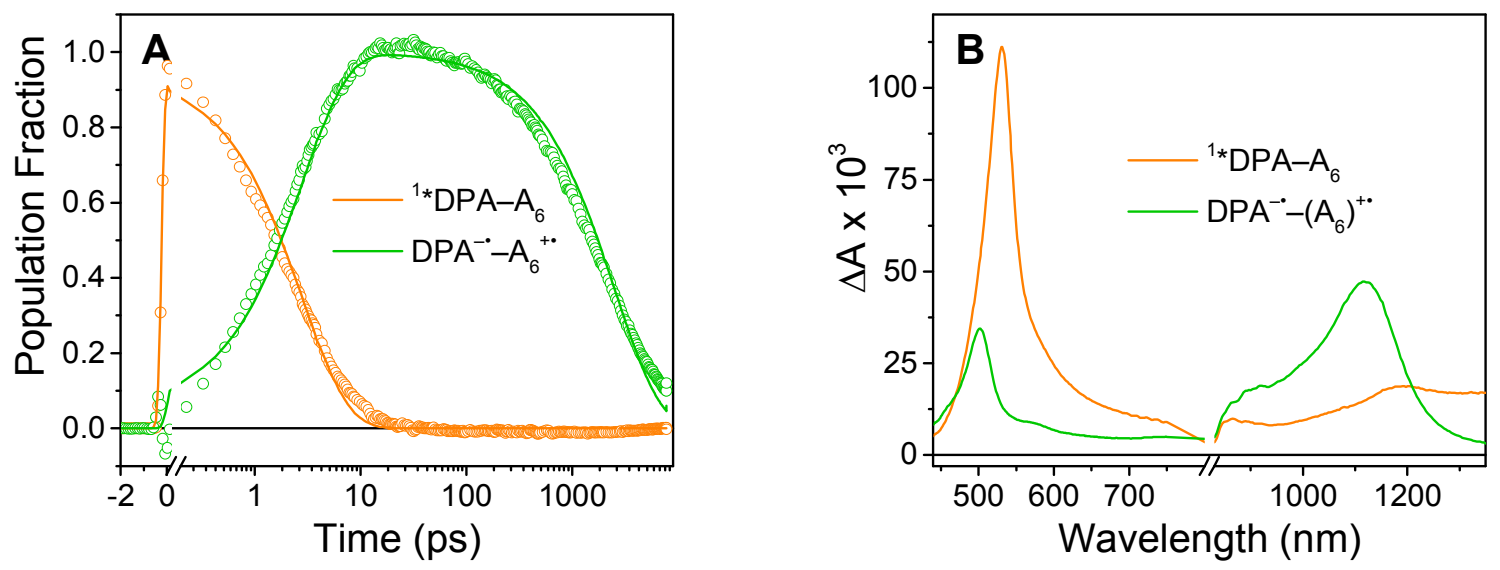

Figure S13. (A) SVD global fit of DPA-A 6 . The raw data (o) and fits (-) are labeled according to the associated species. (B) The Species Associated Spectra (SAS) of the fsTA spectra for DPA- $\mathrm{A}_{6}$ obtained when exciting at $330 \mathrm{~nm}$ and probing in the visible and NIR regions. The associated species are labeled. ${ }^{1}{ }^{*} \mathrm{DPA}-\mathrm{A}_{6}$ has a lifetime of $\tau_{\text {inj }}=2.82 \mathrm{ps} \pm 0.03$ ps. $\mathrm{DPA}^{-\bullet}-\left(\mathrm{A}_{6}\right)^{+\bullet}$ has a lifetime of $\tau_{\mathrm{a}}=2.52 \pm 0.05 \mathrm{~ns}$. Note that the error of the instrument is $\sim 0.2 \mathrm{ps}$ and is the minimum possible error regardless of smaller errors calculated by the program.
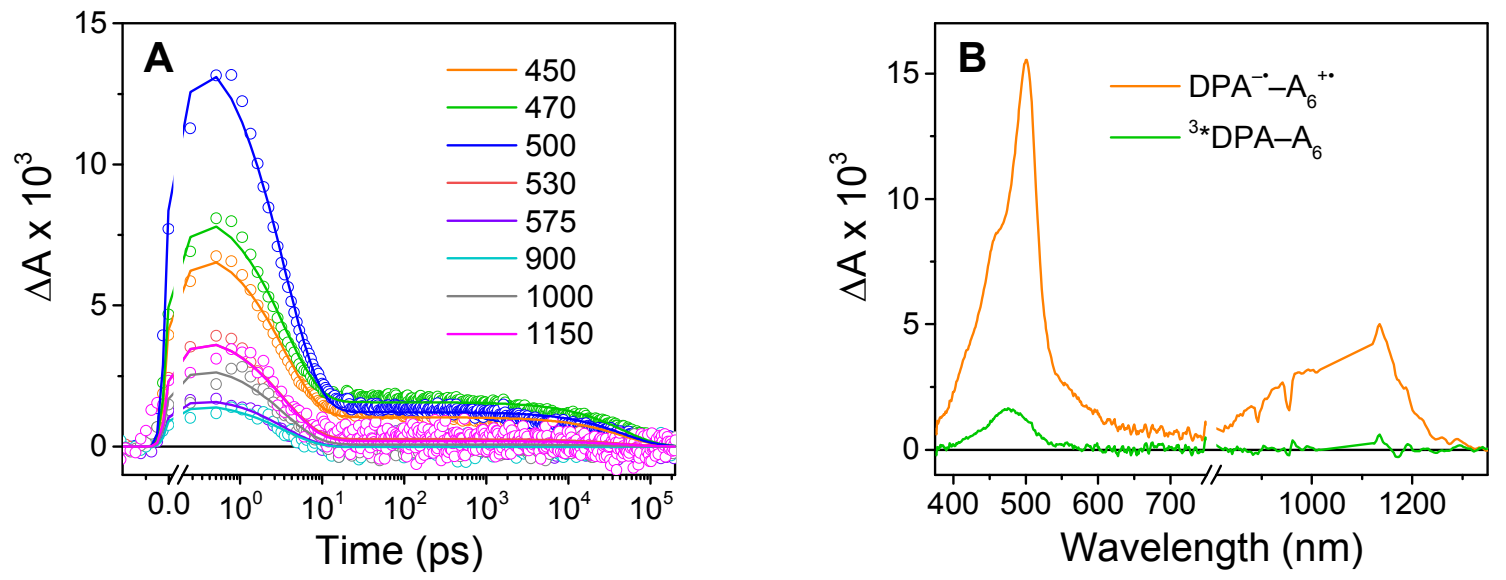

Figure S14. Modified global fit (-) and raw data (o) of indicated key wavelengths (A) and the Species Associated Spectra (SAS) (B) of a first order model of the nsTA spectra for DPA-A 6 obtained when exciting at $330 \mathrm{~nm}$ and probing in the visible and NIR regions. The associated species are labeled. $\mathrm{DPA}^{-\bullet}-\left(\mathrm{A}_{6}\right)^{+\bullet}$ has a lifetime of $3.52 \pm 0.05 \mathrm{~ns}$. The decay constant for the A-polaron measured using the nsTA is less accurate than the fsTA due to the longer step size chosen for obtaining the nsTA out to $200 \mu \mathrm{s}$. For decay constants $<5 \mathrm{~ns}$, the fsTA is more accurate and hence this value is the reported value. The lifetime of ${ }^{3 *} \mathrm{DPA}$ is $47.3 \pm 3 \mu \mathrm{s}$. Note that the error of the instrument is $\sim 0.6 \mathrm{~ns}$ and is the minimum possible error regardless of smaller errors calculated by the program. 


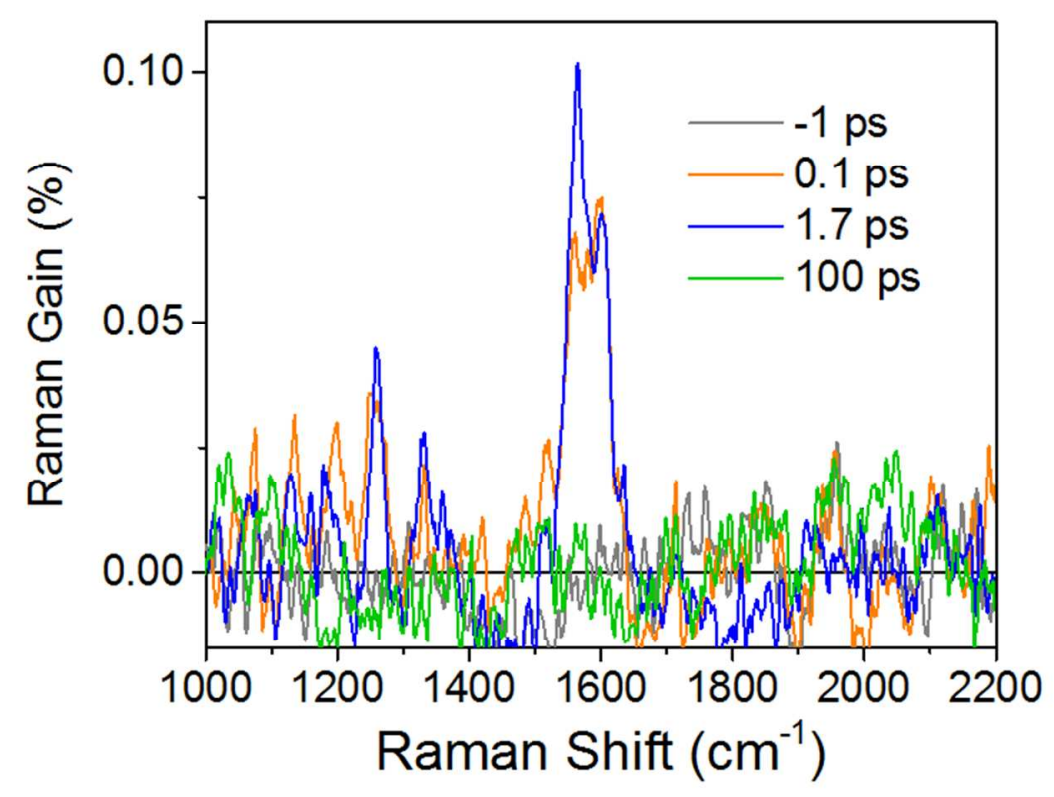

Figure S15. Select FSRS spectra for DPA-G at the indicated delay times obtained using a $575 \mathrm{~nm}$ actinic pump. Delay times were chosen to illustrate a time at peak ${ }^{1}$ *DPA population, peak DPA ${ }^{-}-\mathrm{G}^{+\bullet}$ population, and after charge recombination. These times mirror those chosen for Figure 1 in the main text.
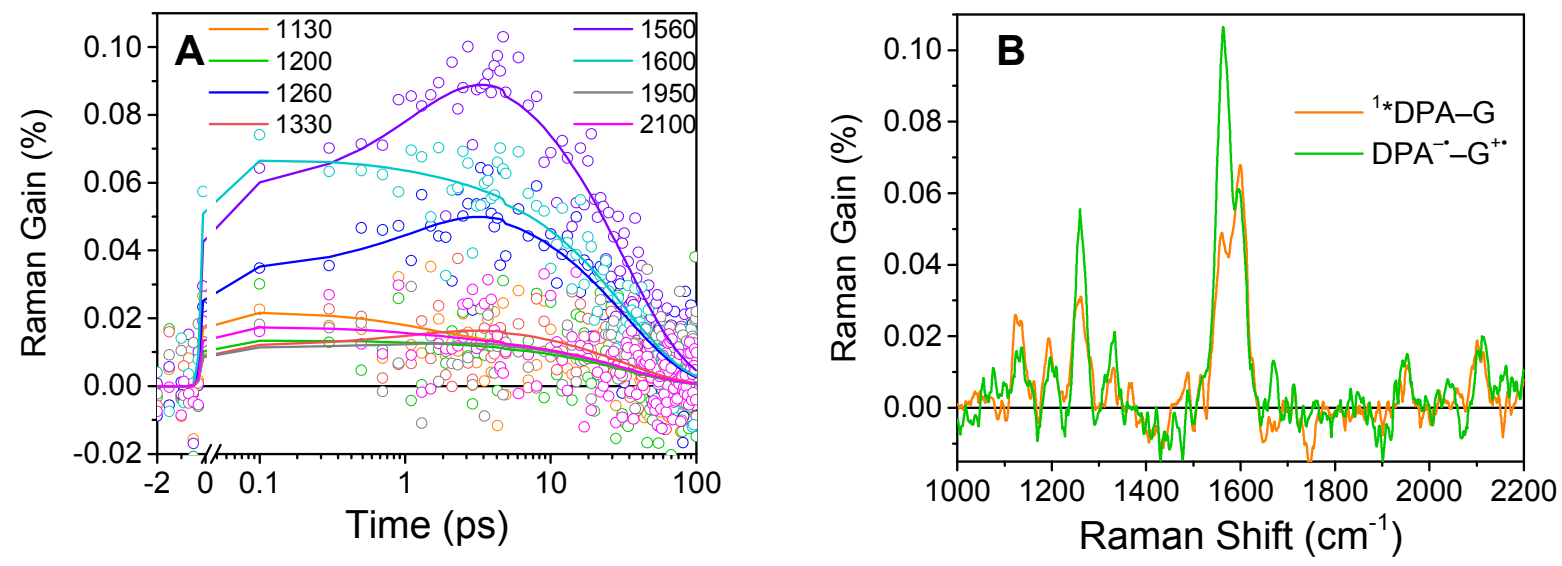

Figure S16. Modified global fit (-) and raw data (o) of indicated key wavelengths (A) and the Species Associated Spectra (SAS) (B) of a first order model of the FSRS spectra for DPA-G. The associated species are labeled. ${ }^{1} * \mathrm{DPA}-\mathrm{G}$ has a lifetime of $\tau_{\mathrm{inj}}=1.35 \pm 0.3 \mathrm{ps} . \mathrm{DPA}^{-{ }^{*}-\mathrm{G}^{+}}$ has a lifetime of $\tau_{\mathrm{crg}}=32.5 \pm 1 \mathrm{ps}$. Note that the error of the instrument is $\sim 0.2 \mathrm{ps}$ and is the minimum possible error regardless of smaller errors calculated by the program. 


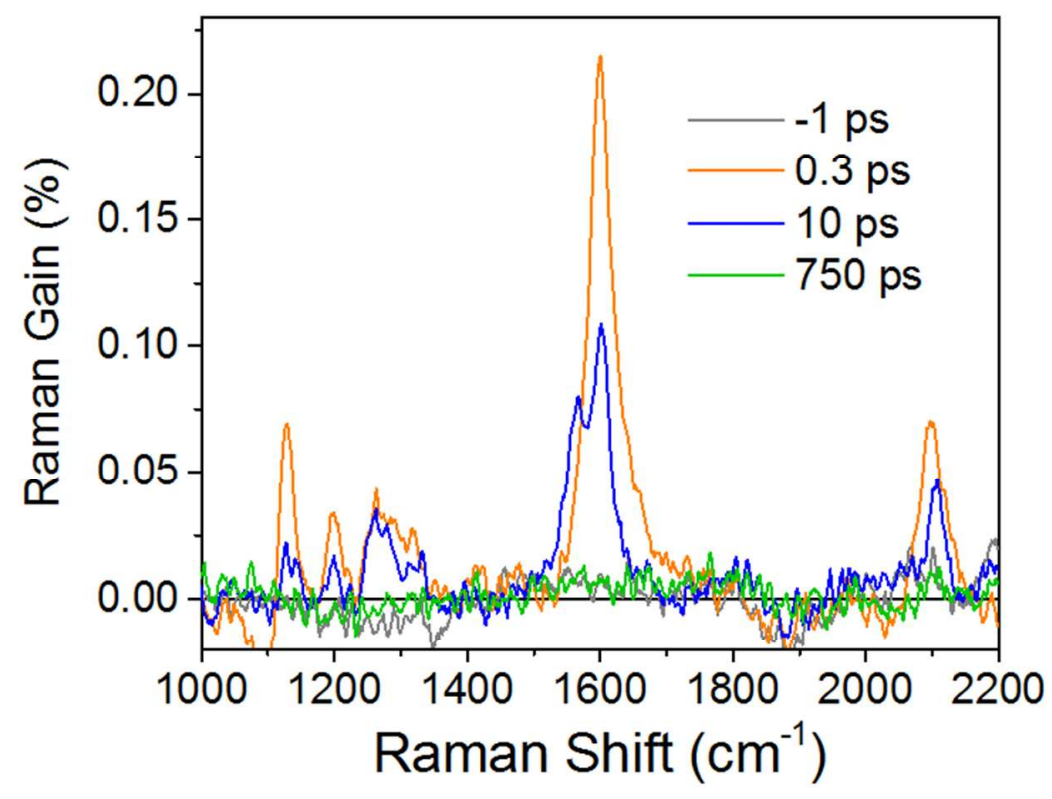

Figure S17. Select FSRS spectra for DPA- $\mathrm{A}_{1} \mathrm{G}$ at the indicated delay times obtained using a $575 \mathrm{~nm}$ actinic pump. Delay times were chosen to illustrate a time at peak ${ }^{1} *$ DPA population, peak DPA ${ }^{-}-\mathrm{A}_{1} \mathrm{G}^{+\cdot}$ population, and after charge recombination. These times mirror those chosen for Figure 1 in the main text.
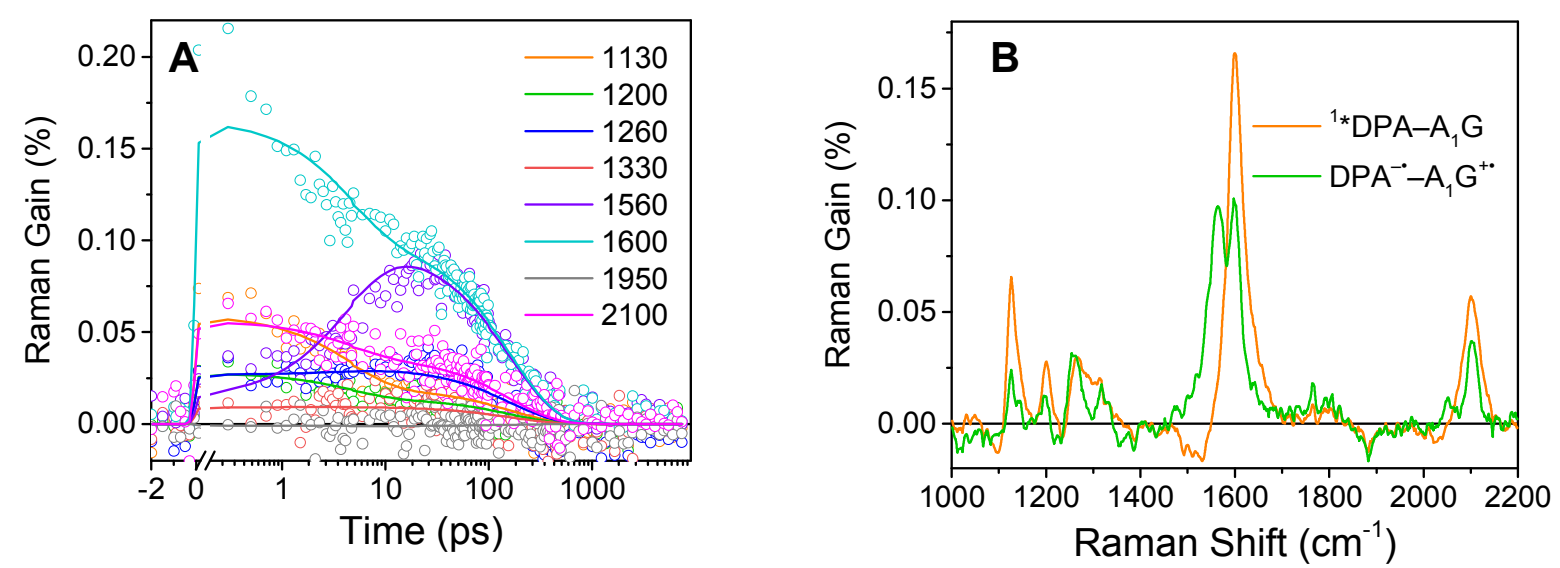

Figure S18. Modified global fit (-) and raw data (o) of indicated key wavelengths (A) and the Species Associated Spectra (SAS) (B) of a first order model of the FSRS spectra for DPA$\mathrm{A}_{1} \mathrm{G}$. The associated species are labeled. ${ }^{1}$ DPA $-\mathrm{A}_{1} \mathrm{G}$ has a lifetime of $\tau_{\mathrm{inj}}=4.64 \mathrm{ps} \pm 0.3 \mathrm{ps}$ and $\mathrm{DPA}^{-\cdot}-\mathrm{A}_{1} \mathrm{G}^{+\bullet}$ has a lifetime of $\tau_{\mathrm{crg}}=168 \pm 5 \mathrm{ps}$. Note that the error of the instrument is $0.2 \mathrm{ps}$ and is the minimum possible error regardless of smaller errors calculated by the program. 


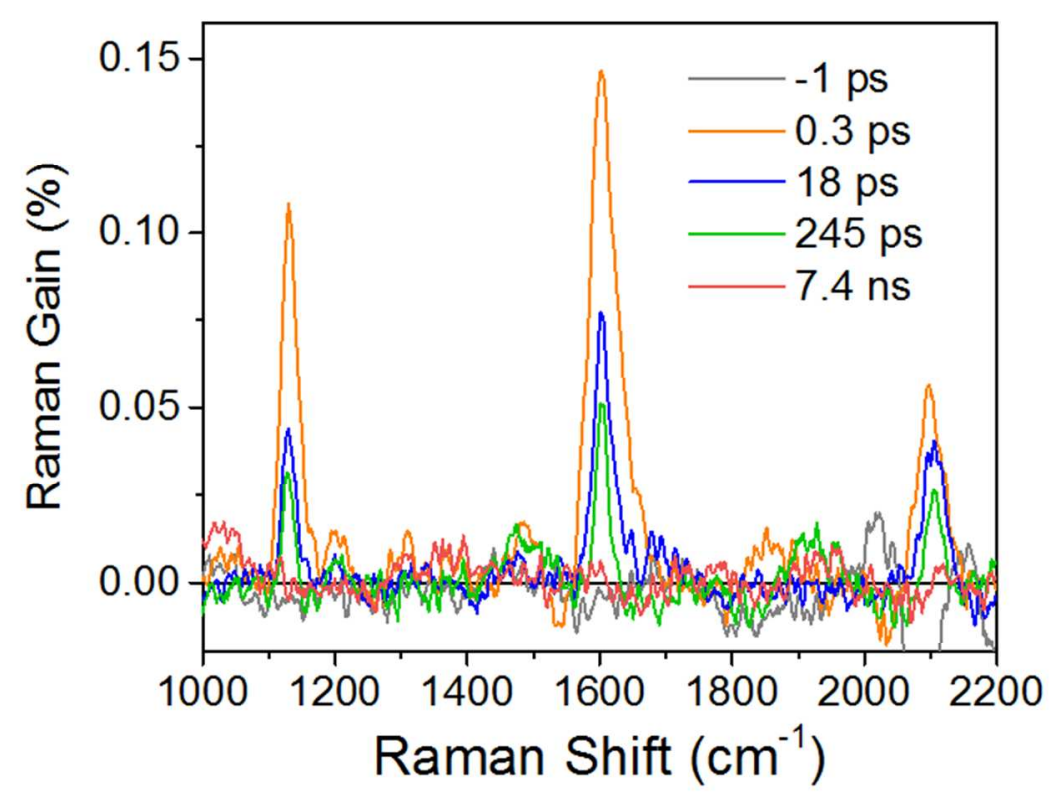

Figure S19. Select FSRS spectra for DPA- $\mathrm{A}_{2} \mathrm{G}$ at the indicated delay times obtained using a $575 \mathrm{~nm}$ actinic pump. Delay times were chosen to illustrate a time at peak population for ${ }^{1} * \mathrm{DPA}, \mathrm{DPA}^{-\bullet}-\mathrm{A}_{2}^{+\bullet} \mathrm{G}$, and $\mathrm{DPA}^{-\bullet}-\mathrm{A}_{2} \mathrm{G}^{+\bullet}$, and after charge recombination. These times mirror those chosen for Figure 1 in the main text.
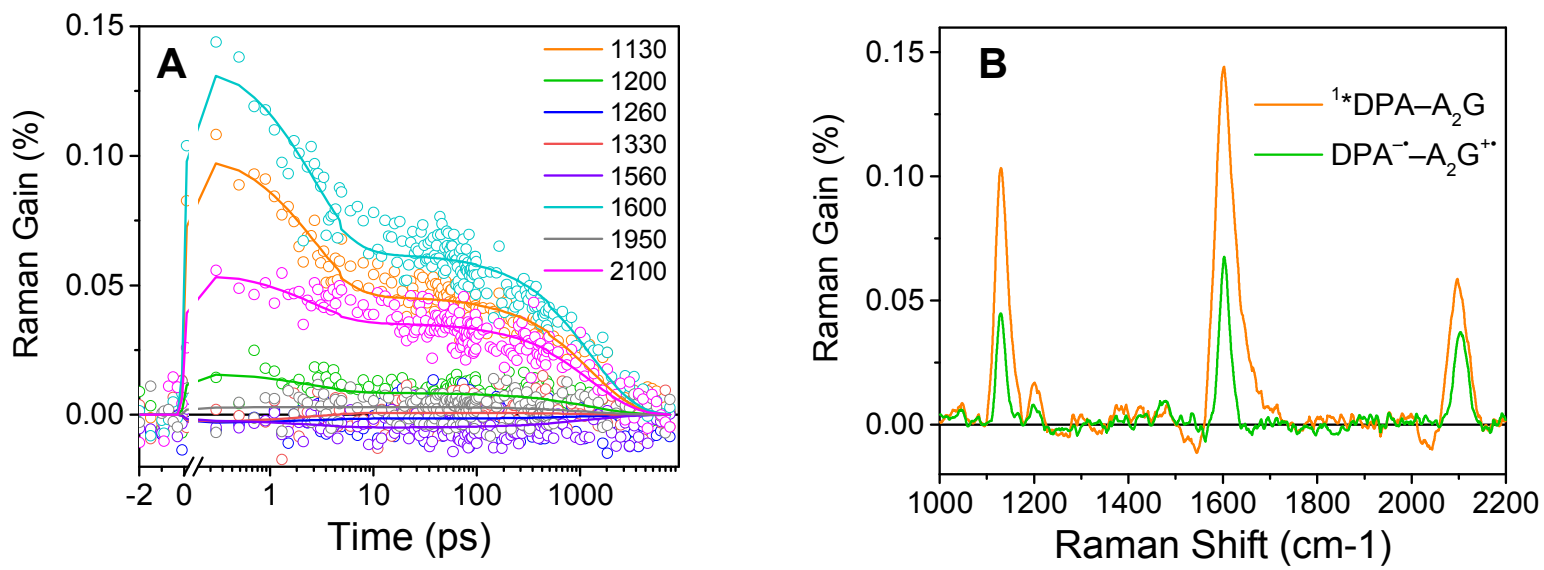

Figure S20. Modified global fit (-) and raw data (o) of indicated key wavelengths (A) and the Species Associated Spectra (SAS) (B) of a first order model of the FSRS spectra for DPA$\mathrm{A}_{2} \mathrm{G}$. The associated species are labeled. ${ }^{1} * \mathrm{DPA}-\mathrm{A}_{2} \mathrm{G}$ has a lifetime of $\tau_{\text {inj }}=2.65 \mathrm{ps} \pm 0.2 \mathrm{ps}$ and $\mathrm{DPA}^{-\bullet}-\mathrm{A}_{2} \mathrm{G}^{+\bullet}$ has a lifetime of $\tau_{\mathrm{crg}}=1.39 \pm 0.06 \mathrm{~ns}$. Note that the error of the instrument is $\sim 0.2 \mathrm{ps}$ and is the minimum possible error regardless of smaller errors calculated by the program. 


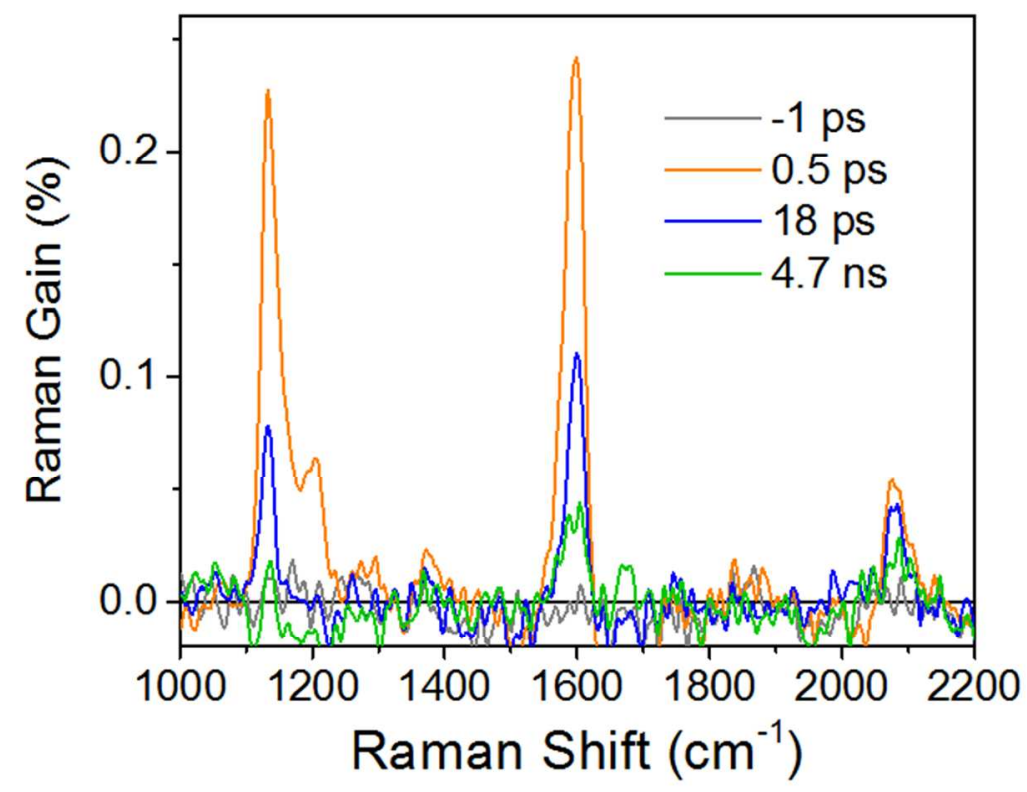

Figure S21. Select FSRS spectra for DPA- $\mathrm{A}_{3} \mathrm{G}$ at the indicated delay times obtained using a $575 \mathrm{~nm}$ actinic pump. Delay times were chosen to illustrate a time at peak population for ${ }^{1 *} \mathrm{DPA}, \mathrm{DPA}^{-\bullet}-\mathrm{A}_{3}^{+{ }^{+}} \mathrm{G}$, and $\mathrm{DPA}^{-\cdot}-\mathrm{A}_{3} \mathrm{G}^{+\bullet}$. Charge recombination from the $\mathrm{G}$ trap does not occur within the time scale of this instrument. These times mirror those chosen for Figure 1 in the main text.
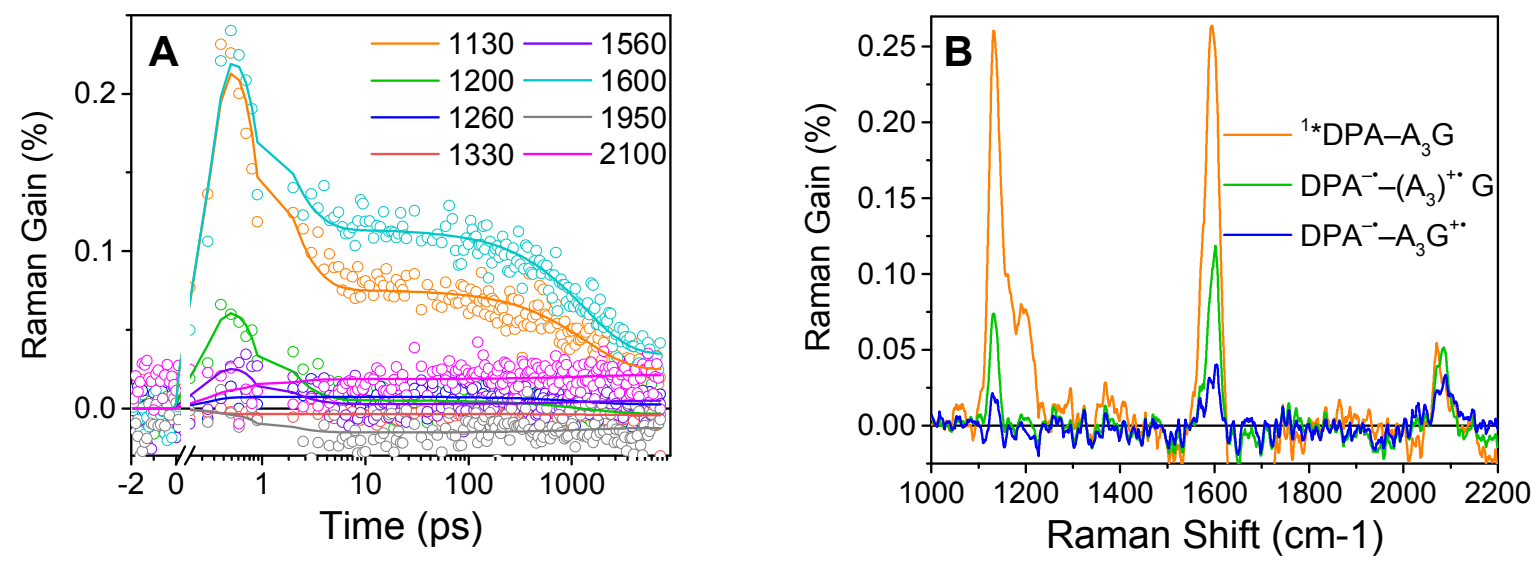

Figure S22. Modified global fit (-) and raw data (o) of indicated key wavelengths (A) and the Species Associated Spectra (SAS) (B) of a first order model of the FSRS spectra for DPA$\mathrm{A}_{3} \mathrm{G}$. The associated species are labeled. ${ }^{1}{ }^{*} \mathrm{DPA}-\mathrm{A}_{3} \mathrm{G}$ has a lifetime of $\tau_{\mathrm{inj}}=1.30 \mathrm{ps} \pm 0.1 \mathrm{ps}$.

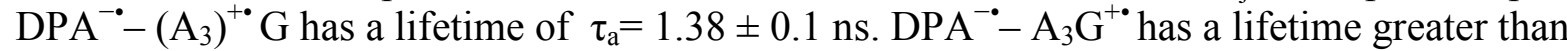
the time window of the fsTA, $>5 \mathrm{~ns}$. Note that the error of the instrument is $\sim 0.2 \mathrm{ps}$ and is the minimum possible error regardless of smaller errors calculated by the program. 


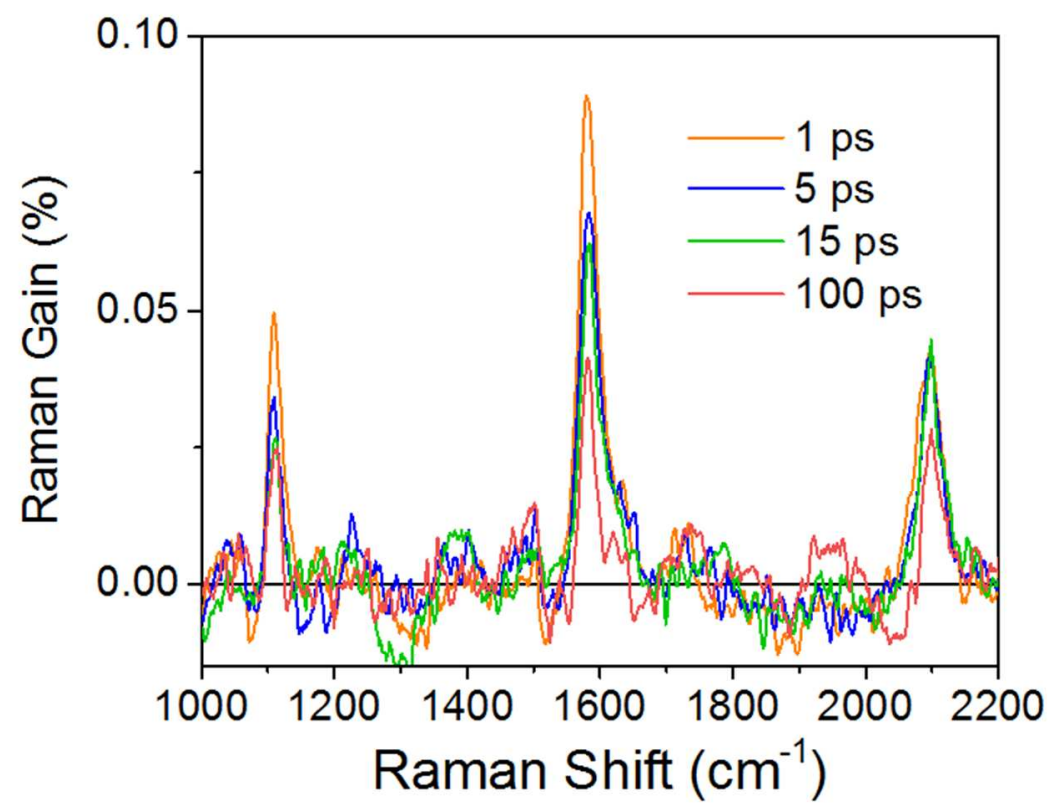

Figure S23. Select FSRS spectra for DPA- $\mathrm{A}_{6}$ at the indicated delay times obtained using a $575 \mathrm{~nm}$ actinic pump. Delay times were chosen to illustrate a time at peak population for ${ }^{1}$ DPA and $\mathrm{DPA}^{-\cdot}-\mathrm{A}_{6}{ }^{+\bullet}$, and a longer time to preclude appearance of other Raman features. Signal to noise of the DPA- $\mathrm{A}_{6}$ sample precluded the possibility of accurate kinetic analysis. 


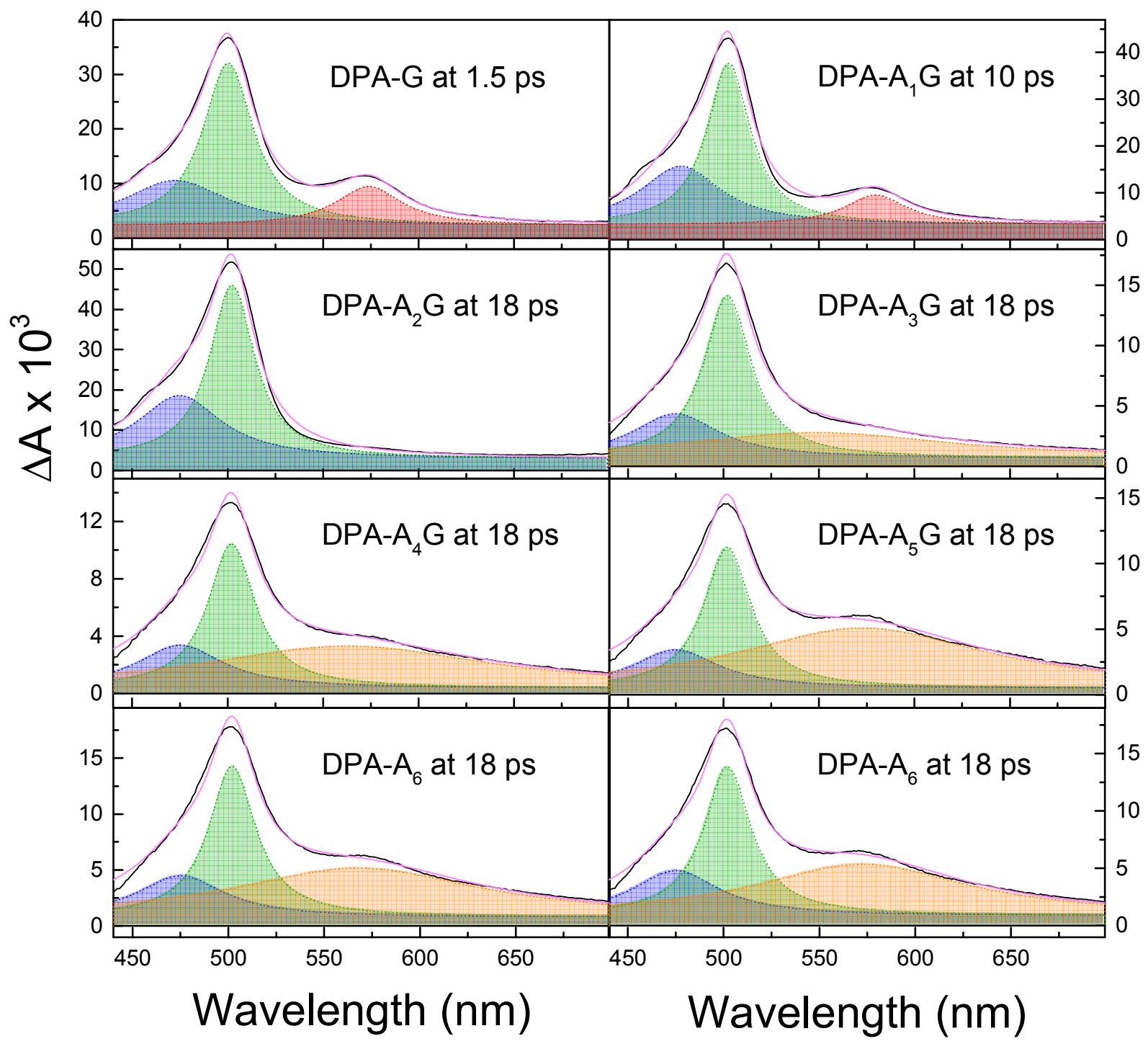

Figure S24. Lorentzian fits of the features for the DPA hairpins indicated. The spectra, black line, are at a time point $6 \times \tau_{\text {inj }}$ as labeled in each graph. The center wavelengths and full widths at half max (FWHM) of the fits are listed in Table S2. The DPA ${ }^{-\bullet}$ feature is fit with two Lorentzians, green and blue, to account for a shoulder. The $\mathrm{G}^{+\bullet}$ feature is fit with one Lorentzian, red, with an average center wavelength of $577 \mathrm{~nm}$ and an average FWHM of 41 $\mathrm{nm}$. The A-polaron feature is fit with one Lorentzian, orange, with an average center wavelength of $565 \mathrm{~nm}$ and an average FWHM of $161 \mathrm{~nm}$. The sum of the Lorentzians is the solid pink line. 
Table S2. Values for Lorentzian Fits of the features in the fsTA spectrum for the DPA hairpins. Fits are shown in Figure S24.

\begin{tabular}{|c|c|c|c|c|c|}
\hline Hairpin & Feature & $\begin{array}{c}\text { Center } \lambda \\
(\mathbf{n m})\end{array}$ & $\begin{array}{c}\text { FWHM } \\
\text { (nm) }\end{array}$ & $\begin{array}{c}\text { Relative } \\
\text { Area }\end{array}$ & $\mathbf{R}^{2}$ \\
\hline DPA-A 6 & $\begin{array}{c}\text { Shoulder } \mathrm{DPA}^{\bullet} \\
\text { Peak } \mathrm{DPA}^{-} \\
\text {Peak }\left(\mathrm{A}_{\mathrm{n}}\right)^{+\bullet}\end{array}$ & $\begin{array}{c}475^{a} \\
502^{a} \\
568\end{array}$ & $\begin{array}{l}55^{a} \\
30^{a} \\
157\end{array}$ & $\begin{array}{l}0.16 \\
0.31 \\
0.53\end{array}$ & 0.994 \\
\hline DPA-G & $\begin{array}{c}\text { Shoulder } \mathrm{DPA}^{\bullet} \\
\text { Peak DPA } \\
\text { Peak G }^{+}\end{array}$ & $\begin{array}{l}473 \\
500 \\
574\end{array}$ & $\begin{array}{l}66 \\
32 \\
43\end{array}$ & $\begin{array}{l}0.30 \\
0.53 \\
0.17\end{array}$ & 0.998 \\
\hline $\mathrm{DPA}-\mathrm{A}_{1} \mathrm{G}$ & $\begin{array}{c}\text { Shoulder } \mathrm{DPA}^{\bullet} \\
\text { Peak DPA } \\
\text { Peak }^{+}\end{array}$ & $\begin{array}{l}478 \\
503 \\
580\end{array}$ & $\begin{array}{l}51 \\
27 \\
39\end{array}$ & $\begin{array}{l}0.35 \\
0.52 \\
0.13\end{array}$ & 0.995 \\
\hline $\mathrm{DPA}-\mathrm{A}_{2} \mathrm{G}$ & $\begin{array}{c}\text { Shoulder DPA }^{\bullet} \\
\text { Peak DPA }\end{array}$ & $\begin{array}{l}475 \\
502\end{array}$ & $\begin{array}{l}54 \\
29\end{array}$ & $\begin{array}{l}0.41 \\
0.59\end{array}$ & 0.995 \\
\hline $\mathrm{DPA}-\mathrm{A}_{3} \mathrm{G}$ & $\begin{array}{c}\text { Shoulder } \mathrm{DPA}^{\bullet} \\
\text { Peak } \mathrm{DPA}^{-} \\
\text {Peak }\left(\mathrm{A}_{\mathrm{n}}\right)^{+\bullet}\end{array}$ & $\begin{array}{c}475^{a} \\
502^{a} \\
549\end{array}$ & $\begin{array}{l}55^{a} \\
30^{a} \\
172\end{array}$ & $\begin{array}{l}0.21 \\
0.42 \\
0.37\end{array}$ & 0.996 \\
\hline $\mathrm{DPA}-\mathrm{A}_{4} \mathrm{G}$ & $\begin{array}{c}\text { Shoulder DPA }^{\bullet} \\
\text { Peak DPA } \\
\text { Peak }\left(\mathrm{A}_{\mathrm{n}}\right)^{+}\end{array}$ & $\begin{array}{c}475^{a} \\
502^{a} \\
563\end{array}$ & $\begin{array}{l}55^{a} \\
30^{a} \\
183\end{array}$ & $\begin{array}{l}0.16 \\
0.30 \\
0.53\end{array}$ & 0.995 \\
\hline $\mathrm{DPA}-\mathrm{A}_{5} \mathrm{G}$ & $\begin{array}{c}\text { Shoulder DPA }^{\bullet} \\
\text { Peak DPA } \\
\text { Peak }\left(\mathrm{A}_{\mathrm{n}}\right)^{+}\end{array}$ & $\begin{array}{c}475^{a} \\
502^{a} \\
573\end{array}$ & $\begin{array}{l}55^{a} \\
30^{a} \\
159\end{array}$ & $\begin{array}{l}0.13 \\
0.27 \\
0.60\end{array}$ & 0.992 \\
\hline $\mathrm{DPA}-\mathrm{A}_{6} \mathrm{G}$ & $\begin{array}{c}\text { Shoulder DPA }^{\bullet} \\
\text { Peak DPA } \\
\text { Peak }\left(\mathrm{A}_{n}\right)^{+}\end{array}$ & $\begin{array}{c}475^{a} \\
502^{a} \\
572\end{array}$ & $\begin{array}{l}55^{a} \\
30^{a} \\
134\end{array}$ & $\begin{array}{l}0.18 \\
0.32 \\
0.50\end{array}$ & 0.994 \\
\hline
\end{tabular}

${ }^{a}$ Values fixed based on Lorentzian fit of DPA- $\mathrm{A}_{2} \mathrm{G}$ due to the overlap of the $\left(\mathrm{A}_{\mathrm{n}}\right)^{+\bullet}$ feature with the $\mathrm{DPA}^{-}$feature. The DPA ${ }^{-\bullet}$ feature in DPA-G and DPA- $\mathrm{A}_{1} \mathrm{G}$ is distinguishable from the $\mathrm{G}^{+\bullet}$ feature and so the Lorentzian fit of the DPA ${ }^{-}$peak and shoulder matches well with that of DPA$\mathrm{A}_{2} \mathrm{G}$. The contribution of the $\left(\mathrm{A}_{\mathrm{n}}\right)^{+\cdot}$ feature in DPA- $\mathrm{A}_{2} \mathrm{G}$ is minor and so the spectrum fits well to two Lorentzians for the $\mathrm{DPA}^{-}$feature alone. The DPA ${ }^{-}$band has shoulder and so cannot be fit with a single Lorentzian. This is similar to the fit of the $\mathrm{SA}^{-}$band as previously described. ${ }^{6}$ 


\section{References for Supporting Information}

(1) Lewis, F. D.; Liu, X.; Miller, S. E.; Hayes, R. T.; Wasielewski, M. R. J. Am. Chem. Soc. 2002, 124, 14020.

(2) Letsinger, R. L.; Wu, T. J. Am. Chem. Soc. 1995, 117, 7323.

(3) Young, R. M. D., S. M.; Barnes, J. C. Juríček, M.; Stoddart, J. F.; Co, D. T.;

Wasielewski, M. R. J. Phys. Chem. A 2013, 117, 12438.

(4) Singh, A. P. N.; Harris, M. A.; Young, R. M.; Miller, S. A.; Wasielewski, M. R.; Lewis, F. D. Faraday Discussions 2015.

(5) Brown, K. E.; Veldkamp, B. S.; Co, D. T.; Wasielewski, M. R. The Journal of Physical Chemistry Letters 2012, 3, 2362.

(6) Young, R. M.; Singh, A. P. N.; K. Thazhathveetil, A.; Cho, V. Y.; Zhang, Y.; Renaud, N.; Grozema, F. C.; Beratan, D. N.; Ratner, M. A.; Schatz, G. C.; Berlin, Y. A.; Lewis, F. D.; Wasielewski, M. R. J. Am. Chem. Soc. 2015, 137, 5113. 